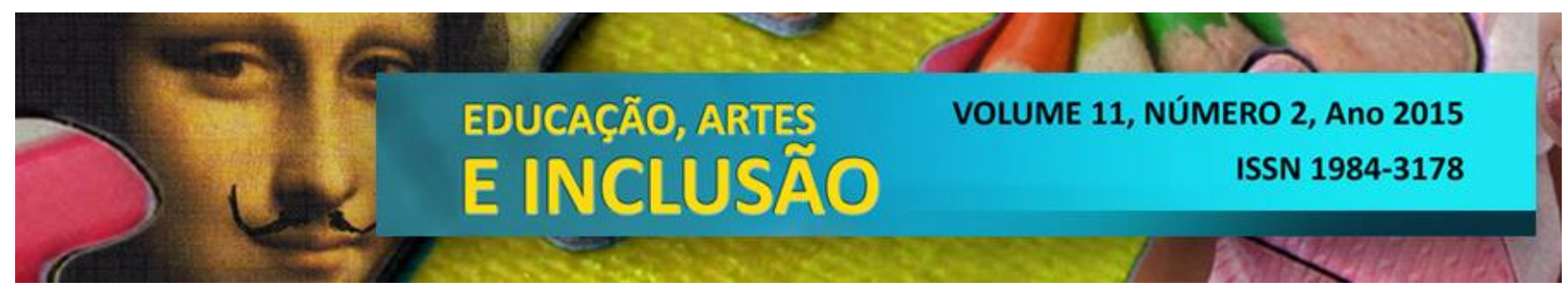

\title{
CRIAÇÃO ARTÍSTICA NA UFMA
}

ARTISTIC CREATION IN UFMA

DOI - http://dx.doi.org/105965/ 198431781122015066

Janine Alessandra Perini - UFMA

\section{RESUMO}

"Criação Artística na UFMA" foi um projeto de extensão ocorrido no ano de 2014, nas dependências da Universidade Federal do Maranhão, Campus de São Bernardo. O objetivo geral foi desenvolver o gosto pela arte, promovendo experiências estéticas. Este projeto propôs oficinas de Artes Visuais uma vez por semana, Ciclo de Filmes uma vez por mês e Exposições uma vez por semestre. Como resultado, a proposta gerou conhecimento e reflexão durante os debates dos filmes; muitos produtos artísticos durante as oficinas, que foram apreciados nas exposições; além de produtos acadêmicos, como artigos e comunicação oral. Concluímos que com este trabalho as práticas artesanais enriqueceram e valorizaram o resgate do trabalho manual, incentivando uma segunda renda familiar para a comunidade de São Bernardo.

PALAVRAS-CHAVE: Arte; Educação; Extensão; Cinema; Oficinas.

\begin{abstract}
"Artistic Creation in UFMA" was an extension project that took place in 2014 in the Federal University of Maranhão in it's São Bernardo's Campus. The goal was to help students developing a taste for art promoting aesthetic experiences. This project has proposed workshops of Visual Arts once a week, cinema cycles once a month and an Art Exhibition once every six months. As a result the proposal has generated knowledge and reflection during the discussions of the films; many artistic products during the workshops which were shown in the exhibitions, as well as academic work such as articles and oral communication. Our conclusion is that with this work, art crafts practices were enriched and gave value to the rescuing of handicraft work, encouraging a second family income for the community of São Bernardo.
\end{abstract}

KEY WORDS: Art; Education; Community; Cinema; Workshop.

\section{Introdução}

Este artigo relata a ação do projeto de extensão "Criação Artística na UFMA", aprovado pelo edital da Universidade Federal do Maranhão, EXT- 2013, submetido pelo Sistema de Informação e Gestão de Projetos (SIGProj), sob a coordenação do Ministério da Educação (MEC). Este se realizou com a duração de um ano, com início em 20/01/2014 e 
término em 20/01/2015, nas dependências da Universidade Federal do Maranhão, Campus de São Bernardo.

A proposta foi elaborada pela Professora de Artes Visuais, Janine Alessandra Perini, do curso de Licenciatura em Linguagens e Códigos da UFMA, Campus de São Bernardo. A equipe executora foi composta por um professor da área de letras, Edmilson Moreira Rodrigues, também do curso de Licenciatura em Linguagens e Código; uma professora da área de história, Fernanda Rodrigues Galve, do curso de Licenciatura em Ciências Humanas da UFMA, Campus de São Bernardo, juntamente com vinte discentes do curso de Licenciatura em Linguagens e Códigos e o apoio de um servidor técnico administrativo.

O projeto teve como público alvo discentes, docentes, servidores da UFMA e a comunidade de São Bernardo. A procura maior foi principalmente das mulheres da comunidade de São Bernardo e dos discentes do Curso de Licenciatura em Linguagens e Códigos.

O objetivo geral deste projeto foi desenvolver o gosto pela arte, promovendo experiências estéticas. Alguns dos objetivos específicos foram: promover a indissociabilidade entre ensino, pesquisa e extensão; aumentar a formação do estudante na geração de novo conhecimento; promover a interdisciplinaridade, por meio das diversas áreas da equipe executora; estreitar os laços entre a universidade e a comunidade de São Bernardo; articular a percepção, a imaginação, a emoção, a sensibilidade e a reflexão ao realizar, contextualizar e fruir produções artísticas presentes na história das diferentes culturas e etnias.

O projeto "Criação Artística na UFMA" constitui-se de três ações pontuais: a primeira, Oficinas Artísticas, uma vez por semana na sala de artes; a segunda, Exposições, com exposições no Hall de entrada do Campus, uma vez por semestre do que foi produzido nas oficinas e a terceira ação, o Ciclo de Filmes, uma vez por mês no auditório do Campus de São Bernardo. 


\section{UFMA: campus São Bernardo}

São Bernardo é um município brasileiro do estado do Maranhão. Sua população é de 26.615 habitantes, segundo estimativa do IBGE em 2009 e sua área é de 1.228,34 km². Uma das características mais marcantes da cidade é a influência política que os grandes oligarcas da cidade exercem sobre a comunidade, além de ser um dos municípios com o nível mais baixo do Índice de Desenvolvimento Humano (IDH) do Brasil.

No município de São Bernardo, existem raros ou nenhum espaço formal para a aprendizagem artística. Devido a essa demanda, a proposta foi oferecer gratuitamente a oportunidade de um aprendizado plástico e visual estruturado, constituindo-se assim, em um espaço democrático para que crianças, jovens e adultos em qualquer condição financeira pudessem ter acesso a esta forma de conhecimento artístico e de manifestação cultural de nossa sociedade. É preciso que se explore de modo mais imperativo o campo social e cultural do município e nada melhor do que uma relação dialógica entre a UFMA e a comunidade.

O Campus da UFMA em São Bernardo é relativamente novo. Surgiu em 2010, com os cursos de Licenciaturas em Linguagens e Códigos, com habilitação em Música ou Língua Portuguesa; Licenciatura em Ciências Humanas, com habilitação em Sociologia e Licenciatura em Ciências Naturais, com habilitação em Química. O objetivo principal com este novo Campus foi o de expandir o leque de atuação e inserção da Universidade no âmbito do Estado do Maranhão, constituindo projetos inovadores de formação de professores com o objetivo de contribuir para a elevação da qualidade do ensino da educação básica. Assim, os três cursos iniciais foram interdisciplinares, criados para sanar a falta de professores com formação superior para ministrarem aulas na educação básica da região.

Atualmente, o Campus, tem contribuído, de forma significativa, para o desenvolvimento da cidade de São Bernardo e região, formando professores nas diferentes áreas de conhecimento em nível de graduação, empreendendo pesquisas voltadas aos 
principais problemas do Estado e da Região, desenvolvendo atividades de extensão, abraçando ações de organização social, de produção, de capacitação de recursos humanos e de valorização da cultura.

O Campus de São Bernardo tem possibilidades reais de ampliar o atendimento à comunidade, pois há espaços disponíveis no Campus São Bernardo e pessoal qualificado para atuar em novas propostas. Com isso, o projeto "Criação Artística na UFMA”, ofereceu uma oportunidade para que pessoas interessadas em arte, mas que não possuíam acesso a cursos de graduação, por exemplo, pudessem acessar conhecimentos restritos ao universo acadêmico.

Assim, o objetivo foi o de desmistificar a produção artística, considerada como algo restrito apenas a quem tem o domínio técnico, e estimular a produção artística dos participantes, refletindo sobre a sua própria linguagem e a linguagem de outros artistas. Dessa forma, deu-se o início das Oficinas Artísticas.

\section{Oficinas artísticas e exposições}

As oficinas de Artes Visuais aconteceram durante um ano, com encontros semanais, com duração de 4 horas no período matutino, na sala de Artes, da UFMA, Campus de São Bernardo. Os participantes eram principalmente alunos do curso de Linguagens e Códigos e mulheres da comunidade de São Bernardo, estas mulheres tinham como profissão "Do lar", algumas já faziam artesanato e queriam aprimorar, outras visavam a socialização e a integração com a universidade. O objetivo desta proposta não era formar artistas, mas estimular o interesse, oferecer a oportunidade, possibilitar a experimentação de diferentes práticas artísticas, orientado de maneira individualizada para que o aluno pudesse encontrar sua própria linguagem. Além da produção, nosso foco também foi a decodificação e a interpretação das imagens, buscando promover a formação artística e estética do aprendiz e a sua participação na sociedade.

Muito se tem pensado sobre a produção da imagem; igualmente, muito se tem estudado sobre a história da imagem; no entanto, nem sempre é lembrado o que, à maioria das pessoas, talvez seja mais importante: a leitura da imagem. Isso implica em tornar o sujeito mais do que um mero espectador ou receptor, mas um enunciatário da imagem, isto é, um interlocutor que também produza significados, um leitor que de certa forma 


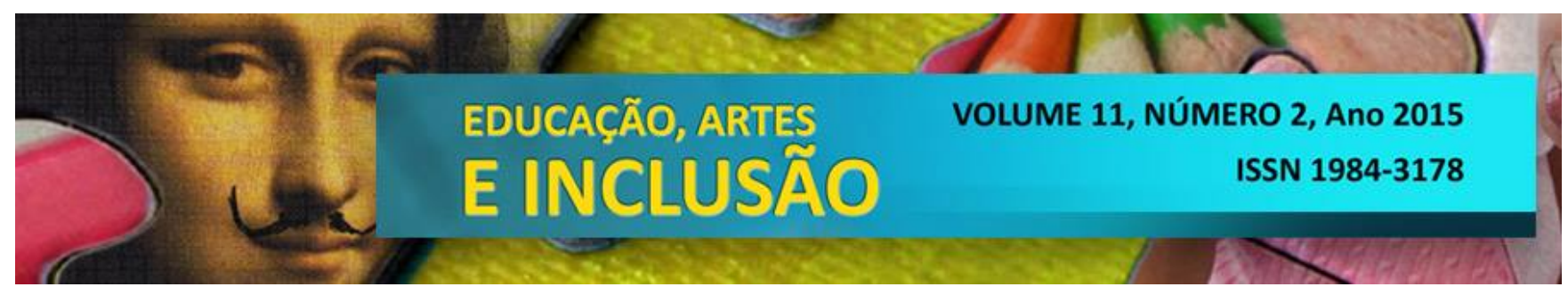

recrie a imagem. Os elementos estéticos estão aí, presentes no cotidiano de cada ser humano; cabe então compreendê-los (OLIVEIRA, 1999, p.1).

Buscou-se, como afirma Oliveira, formar interlocutores, pessoas que produzam significados, que de certa forma recriem a imagem. Sabemos que vivemos em um mundo com muitas imagens, em que as possibilidades de produção e de reprodução são infinitas. Artes e culturas visuais são informações. Fernando Hernandez definiu cultura visual:

\begin{abstract}
A expressão cultura visual refere-se a uma diversidade de práticas e interpretações críticas em torno das relações entre as posições subjetivas e as práticas culturais e sociais do olhar. (...) do movimento cultural que orienta a reflexão e as práticas relacionadas a maneiras de ver e de visualizar as representações culturais e, em particular, refiro-me às maneiras subjetivas e intrasubjetivas de ver o mundo e a si mesmo (HERNÁNDEZ, 2007, p.22.).
\end{abstract}

Estimular a leitura das culturas visuais, é estimular a leitura de mundo e de si mesmo, é produzir conhecimento. Assim, estas oficinas propuseram criar diálogos com as artes e culturas visuais por meio da reflexão e da produção artística, oferecendo um ponto de partida para um fazer artístico particular, um fazer fundamentado em referências e reflexões.

Lanier (2013) nos traz que a experiência estética visual, já é desfrutada pelos seres humanos, mesmo sem ir à escola. Por isso, nós professores não a introduzimos, mas a incrementamos a partir de algo que já está lá:

Se o indivíduo tem efetivamente uma experiência estética, visual assim como outras, antes de entrar para a escola ou fora dela, então, quais são os estímulos que provocam essas reações? Um deles parece ser provavelmente o meio natural. Não precisamos ter tido um curso de apreciação artística no colégio ou mesmo uma atividade de batik na faculdade para reagir com admiração e prazer perante um belo pôr-do-sol ou de uma sequoia gigante ou de um oceano verde-azulado. Outro estímulo é, evidentemente, a tradição de artesanato popular: aquelas colchas feitas pela vovó, a velha mobília que herdamos de nossas famílias, o porta-guardanapos esculpido de barbantes de baleia. Estes não são propriamente a arte nobre dos museus mas frequentemente, nos proporcionam pelo menos o mesmo tipo de prazer de visão que associamos às mais honoríficas artes (LANIER, 2013, p.74).

Vicent Lanier explica a importância de trabalhar não apenas com obras a óleo em molduras douradas ou esculturas em mármore sobre pedestal dos museus, mas também, com $\mathrm{o}$ artesanato e a arte popular. 


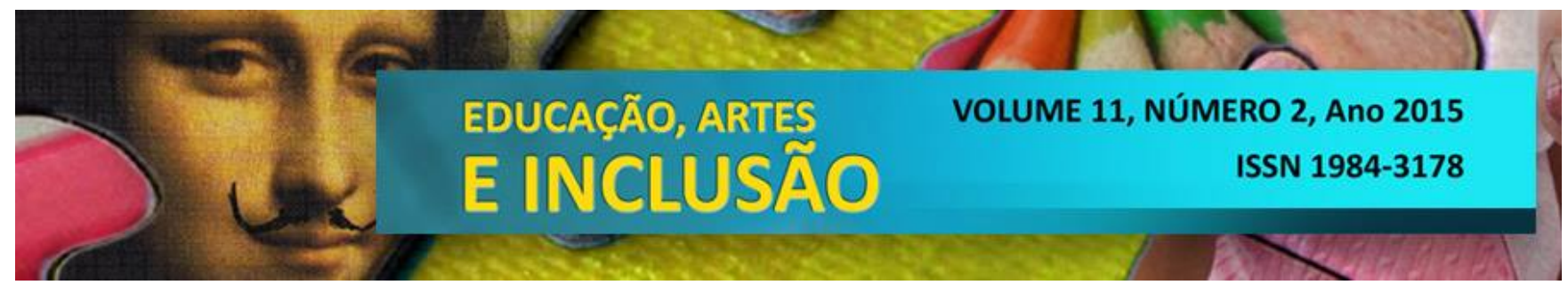

Nas oficinas, os participantes foram orientados individualmente conforme a linguagem plástica desenvolvida. Essas orientações foram realizadas em torno de aspectos teóricos (referências artísticas, temática, poética) e aspectos práticos (possibilidades e experimentações de diferentes técnicas). O trabalho se desenvolveu por meio de experimentações práticas e reflexões teóricas. Em cada mês foi executado uma técnica diferente, discutida e planejada antecipadamente pelos membros da equipe executora do projeto.

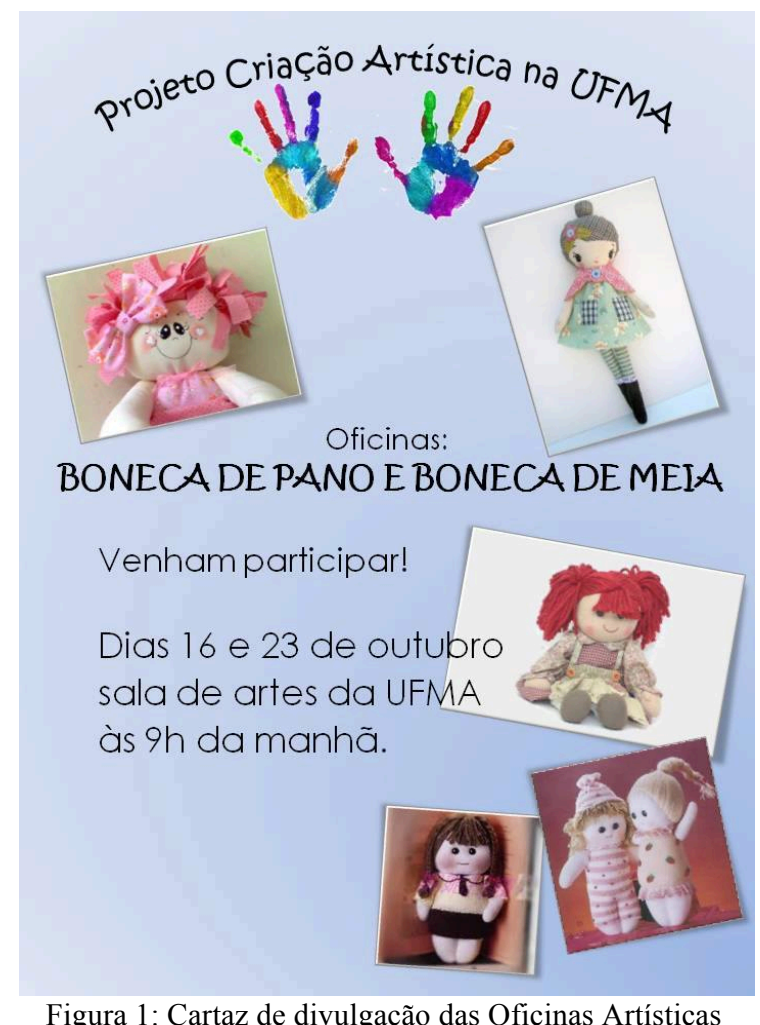

A Figura 1 apresenta o cartaz de divulgação de uma das técnicas desenvolvidas nas Oficinas Artísticas. Para cada técnica era produzido pela equipe executora um cartaz para sua divulgação.

Os participantes realizavam experiências estéticas, explorando o fazer artístico, fruindo a obra de arte, refletindo e conhecendo sobre arte. Os participantes ampliaram a sensibilização, a percepção, a imaginação e a reflexão, no que diz respeito à valorização da arte.

O projeto foi pensado com trocas de experiências e conhecimentos entre os participantes e o professor, enfatizando o processo do participante, o qual não é estático e nem 
linear. Segundo Vygotsky (2002), o aprendizado de cada indivíduo está ligado ao ambiente em que vive e depende do acesso aos instrumentos físicos (talheres, ferramentas, mesa, etc) e símbolos (cultura, valores, crenças, costumes, tradições, sistemas de representação, conhecimentos), desenvolvidos em gerações anteriores. Isso implica em uma ação partilhada, já que é por intermédio dos outros que as relações entre sujeito e objeto de conhecimento são estabelecidas ao longo do desenvolvimento humano e do social para o individual. Nesse ambiente social em que o projeto se construiu, o participante interagiu com instrumentos e técnicas diversas, tendo a mediação do professor e dos outros participantes para a construção do seu desenvolvimento.

Para Marx (2003), as mudanças históricas na vida material e na sociedade é que determinam mudanças na consciência do homem: "O modo de produção da vida material condiciona o desenvolvimento da vida social, política e intelectual em geral. Não é a consciência dos homens que determina o ser; é o seu ser social que, inversamente, determina a sua consciência" (MARX, 2003, p.5).

Nestes encontros sociais, entre comunidade e universidade, o projeto Criação Artística na UFMA proporcionou aos participantes a experiência social e a experiência da criação. Para Vygotsky (2009), a atividade criadora do homem é aquela em que se cria algo novo. Nós, seres humanos, podemos reconhecer dois tipos básicos de comportamento: um pode ser chamado de reconstituidor ou reprodutivo e o outro de combinatório ou criador. A primeira, intimamente ligada à memória, em sua essência consiste em reproduzir ou repetir impressões ou ações anteriores a sua experiência. Mas o cérebro, diz Vygotsky, também possui a capacidade para enfrentar com sucesso e resolver problemas novos e diferentes aos já conhecidos. É a capacidade de unir e criar algo novo, utilizando elementos de situações adquiridas antes de aplicá-los a novos problemas. Qualquer atividade humana que não se limita a reproduzir fatos vivenciados, mas que cria novas imagens, novas ações, pertence a esse segundo tipo de comportamento, ou seja, combinatório ou criador. A criação é condição necessária da existência e ela já se manifesta na mais tenra infância em todos os indivíduos e não apenas nos gênios. 


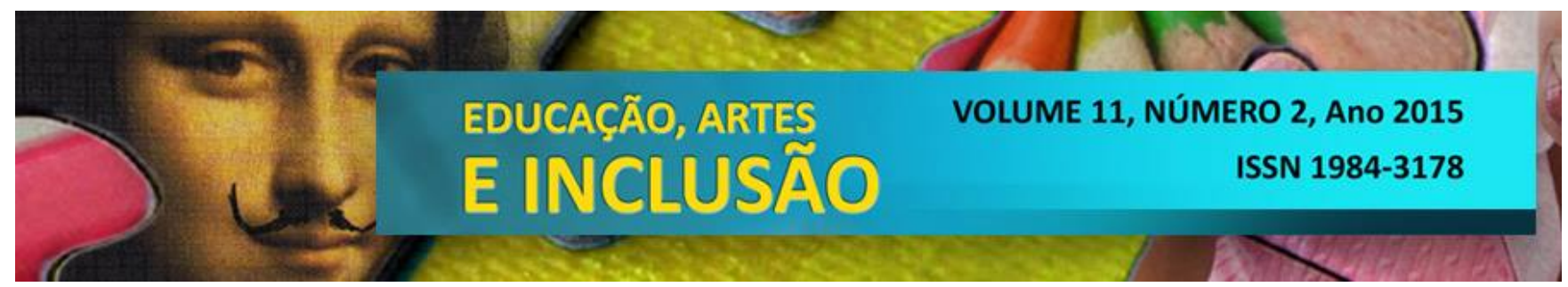

Por isso, as Oficinas Artísticas ampliaram nos participantes a criatividade e a imaginação, por meio de técnicas artísticas desenvolvidas como podemos observar na Figura 2 abaixo:

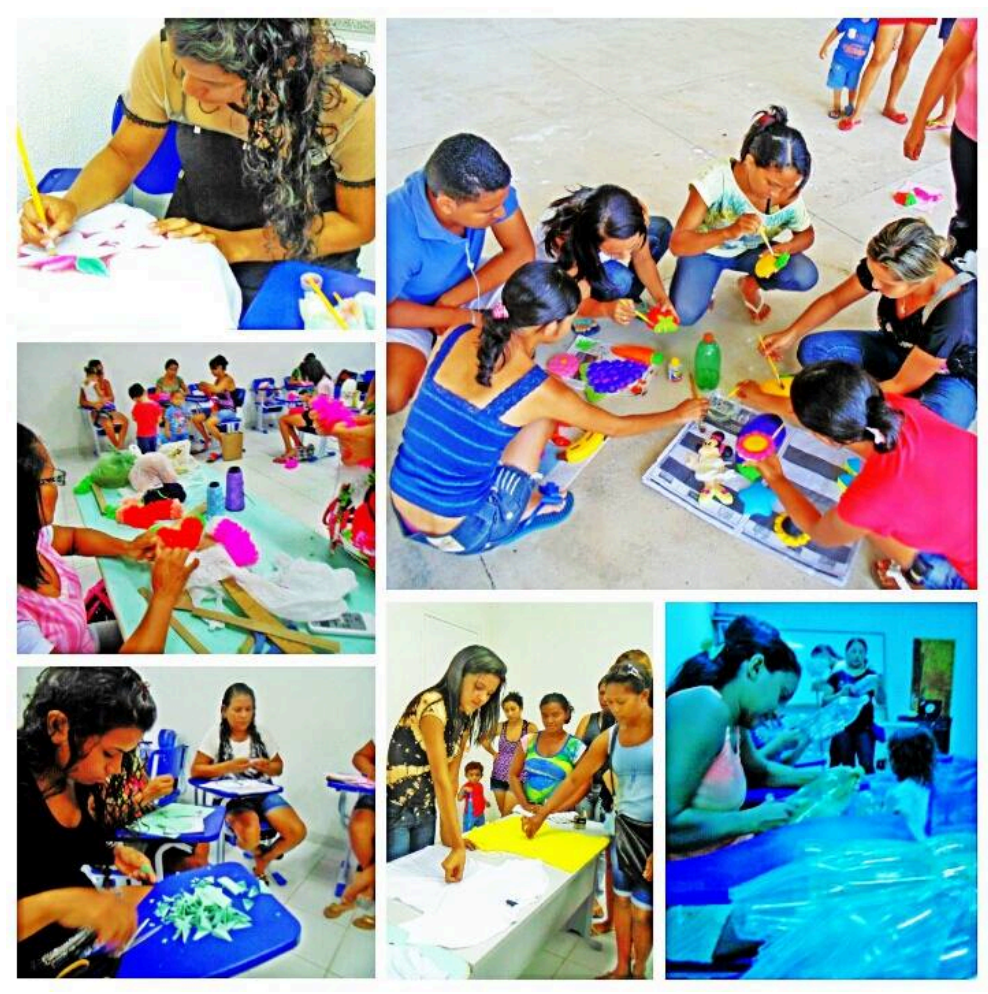

Figura 2: Fotos das Oficinas Artísticas Fotos: Janine Alessandra Perini

Pode-se observar na Figura 2 as diversas técnicas ministradas durante o ano como: a oficina de boneca de pano, boneca de lã, pintura em tecido, a técnica de Tye-dye nas camisetas, pintura em gesso, objetos criados a partir de garrafa pet e criados por meio de papel, origami.

A oficina de boneca de pano e boneca de lã buscou-se o resgate do lúdico, do brincar, do brinquedo feito em casa, valorizando o legado histórico e cultural. Com a oficina de pintura em pano e pintura em gesso, valorizou-se o objeto utilitário e o objeto decorativo, valorizando a arte no cotidiano das pessoas. Com as oficinas de Tye-dye, garrafa pet e origami foi trabalhado com o conceito de reciclagem, refletindo, analisando e trazendo para 


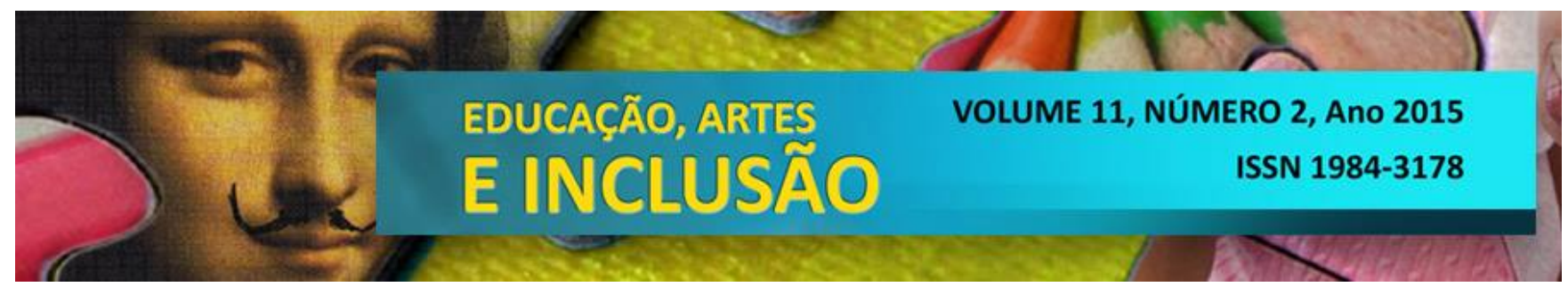

nossa realidade termos como desperdício, reaproveitamento, reutilizar, preservação do meio ambiente.

Os resultados das oficinas foram apresentados nas exposições, que aconteceram uma vez por semestre, a primeira em junho e a outra em dezembro de 2014. As atividades foram realizadas no hall de entrada do Campus de São Bernardo, UFMA, expondo as produções realizadas nas Oficinas Artísticas.

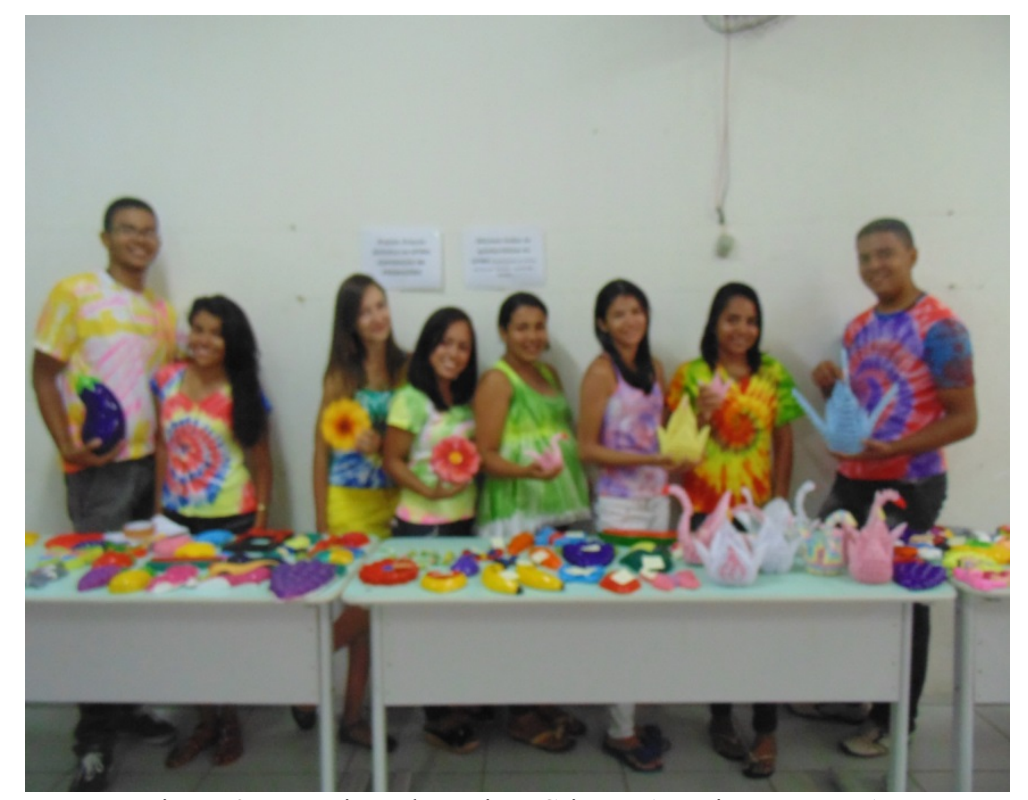

Figura 3: Exposição do projeto Criação Artística na UFMA Foto: Janine Alessandra Perini

Na Figura 3, alguns membros da equipe de execução do projeto, vestidos com as camisetas produzidas durante as Oficinas Artísticas com a técnica de Tye-dye, em cima da mesa, esculturas em gesso e origami, trabalhos confeccionados durantes as oficinas.

\section{Ciclo de filmes}

O Ciclo de Filmes ocorreu uma vez por mês, no período noturno, no auditório do Campus de São Bernardo, com debate no final de todas as sessões. Os filmes foram escolhidos e debatidos pelos membros da equipe executora do projeto e divulgados para a comunidade interna e externa da universidade. Essa divulgação foi realizada por meio digital, 


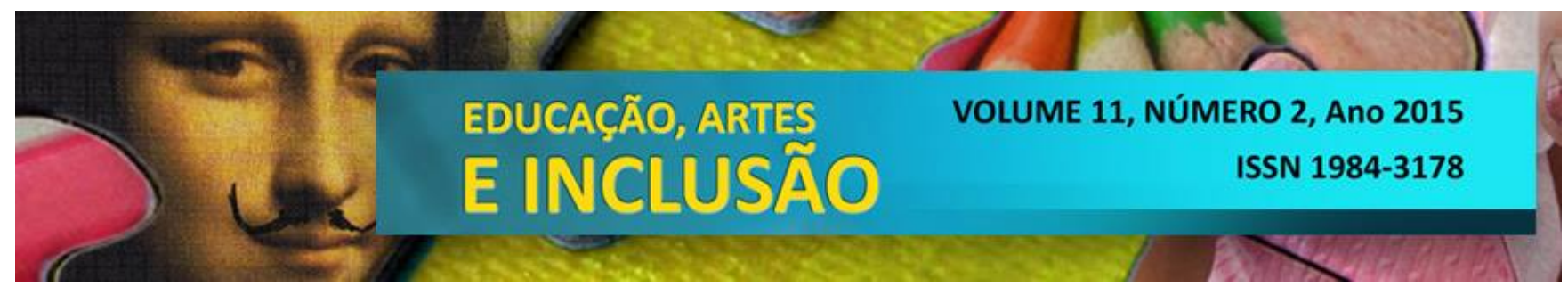

sites de relacionamentos (Facebook) e por cartazes espalhados na UFMA, escolas públicas, posto de saúde, mercados e padarias da cidade.

Em relação à escolha dos filmes, o grupo decidiu homenagear os filmes brasileiros, selecionando alguns que retratavam a realidade brasileira. Tentamos fazer essa triagem com responsabilidade e intencionalidade educativa:

Quando falamos de responsabilidade e de intencionalidade educativas para a exibição de um filme em sala de aula, nos referimos à importância de aprender a selecionar e analisá-lo para que não se perca essa condição que tem a obra fílmica de também ser uma fonte de encontros com os mais distintos contextos, ser realista nos fatos que narra - sem ser realidade - e relacioná-los a processos e experiências humanas significativas (PIMENTEL, 2011, p.85).

Nesses encontros e experiências significativas, foi criado um espaço não apenas para admirar o filme, mas também para debater e refletir. O meio para chegar a esse objetivo foi o cinema, pelo fato de ser audiovisual. E assim, retratar a realidade, não como ela é, mas como afirma Pimentel (2011), como um meio de "enlaçar" o espectador pelo emocional e psicológico, visto que anseia ver nas telas seus desejos, contradições, conflitos e necessidades.

Por isso, o grupo pensou em abordar como o cinema apresenta a realidade e como usar este veículo para fins educacionais. O objetivo não era filmes com moldes convencionais apresentados pelo cinema norte americano (hollywoodiano) e sim, filmes que retratassem a realidade "nua e crua" de uma sociedade em pleno caos e destruição, e que conseguiram suprir as necessidades de uma época instável e sem recursos econômicos e tecnológicos para altas e lucrativas produções cinematográficas.

Leite (2005) apresenta um histórico sobre a indústria cinematográfica brasileira e mostra que este passou por um processo de várias dificuldades e uma delas foi a grande concorrência das indústrias Hollywoodianas, em que estas se fortaleceram após a primeira guerra mundial como a maior e mais influente "fabrica de sonhos". Outra dificuldade foi no período da Ditadura Militar onde a censura do Estado entra em cena, e intervém em alguns filmes. 


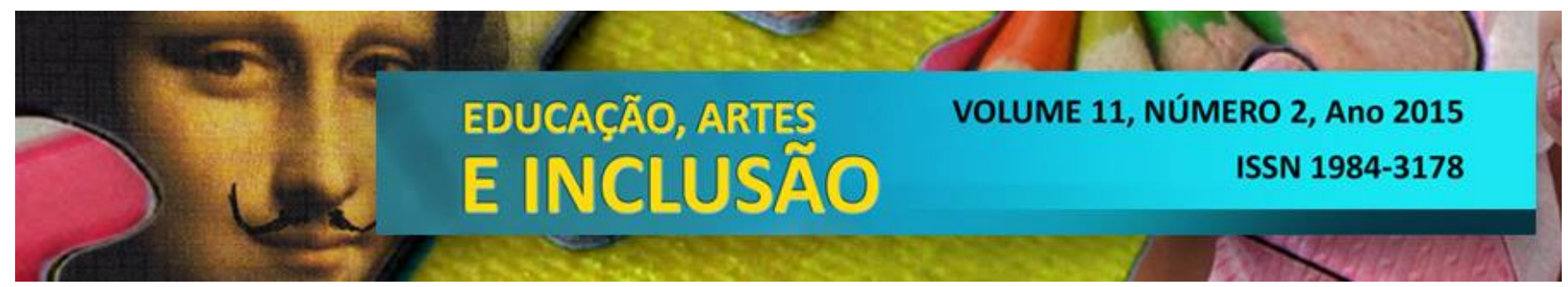

Percebeu-se, durante as reuniões de estudos, que alguns produtores brasileiros não veem mais valia nas obras cinematográficas de ficção fantasiosas aqui produzidas, pois o que interessava a eles era uma abordagem mais realista possível, que discutisse questões mais urgentes, como, por exemplo, a pobreza, a vida das pessoas à margem da sociedade e a corrupção.

\begin{abstract}
Os cineastas voltam-se para o dia-a-dia de proletários, camponeses e pequena classe média. A rua e ambientes naturais substituem os estúdios. Atores pouco conhecidos ou até não profissionais aparecem no lugar de vedetes célebres. A linguagem simplifica-se, procurando captar este cotidiano e tentando ficar sempre apegada aos personagens e suas reações nas difíceis situações cotidianas (BERNADET, 1985? p.50).
\end{abstract}

Um cinema que capta o difícil cotidiano, representado por pessoas e não atores célebres, como os astros e estrelas encontrados no cinema norte americano (hollywoodiano). Além deste novo conteúdo, percebeu-se que em alguns filmes brasileiros foram revolucionários no que diz respeito à feitoria dos próprios filmes, com a premissa de "uma câmera na mão e uma ideia na cabeça" (GLAUBER ROCHA), que surge pela falta de recursos financeiros e pela pouca quantidade de pessoas trabalhando na produção dos filmes.

O que se vê adiante no cinema brasileiro é a valorização em relação aos problemas sociais vivenciados no país e um grande número de adeptos a essa nova forma de filmar e retratar a realidade. Consequentemente, essa nova maneira de pensar/fazer os filmes torna-se uma marca registrada das produções nacionais.

Conferido ao cinema a arte do real, é de fundamental importância observar que este instrumento não trata verdadeiramente da "realidade", só faz parecer real aquilo que nos é apresentado. Sobre esta impressão de realidade, explica Bernardet (1985?):

Um pouco como num sonho: o que a gente vê e faz num sonho não é real, mas isso só sabemos depois, quando acordamos. Enquanto dura o sonho, pensamos que é verdade. Essa ilusão de verdade, que se chama impressão de realidade, foi provavelmente a base do grande sucesso do cinema. O cinema dá a impressão de que é a própria vida que vemos na tela, brigas verdadeiras, amores verdadeiros. Mesmo quando se trata de algo que sabemos não ser verdade [...] (BERNARDET, 1985?, p. 5). 


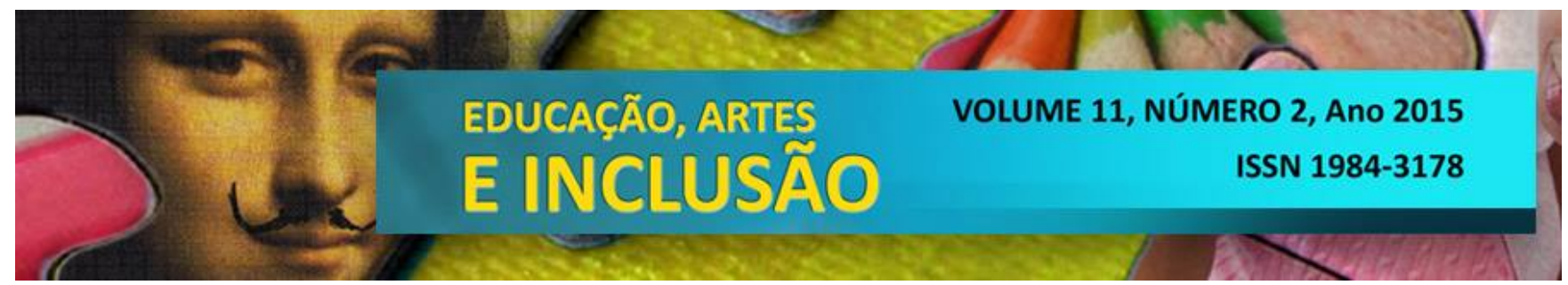

É por essa impressão de realidade, que se deu a escolha dos filmes. O primeiro filme foi $O$ contador de histórias, de Luiz Villaça. Após a apresentação, propôs-se um momento de debate e reflexão a respeito de questões sociais, políticas, educacionais e culturais vinculadas à comunidade local, a comunidade de São Bernardo.

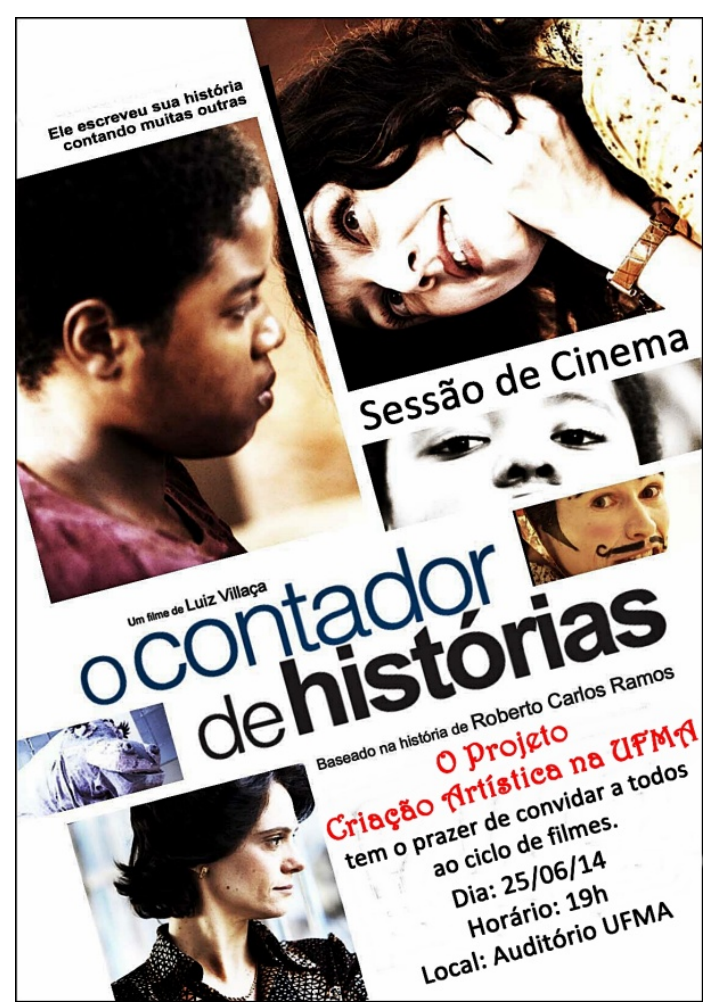

Figura 4: Cartaz de divulgação do filme: O contador de História

A Figura 4 apresenta o cartaz de divulgação do filme biográfico brasileiro de 2009, $O$ contador de histórias, que se baseia na vida de um contador de história de Belo Horizonte, MG, Roberto Carlos Ramos que foi levado para a FEBEM (Fundação Estadual do Bem Estar do Menor) no intuito de melhorar a sua vida. Todavia, esse sonho, galgado por sua mãe, tomou um rumo inesperado: a criminalidade. 
O filme se passa nos anos 70, época essa em que a FEBEM era a mais nova instituição educacional criada pelo governo militar, no intuito de melhorar as condições socioeducativas da época, mas não é o que se constata diante dos fatos abordados no longa-metragem.

Roberto Carlos Ramos, personagem central da história, é filho caçula de dez irmãos, que vivem numa favela de Belo Horizonte, em estado de pobreza. Sua mãe, na esperança de ainda ver um dos filhos se tornar alguém na vida, é iludida por uma propaganda, que promete que a FEBEM irá tornar médico, advogado, engenheiro aquela criança que fizer parte do corpo de alunos da instituição. Pimentel (2011) traz para nossa realidade a influência que a mídia exerceu sobre a mãe de Roberto:

As mídias, com seu poder de manipulação e persuasão, afetam as condições humanas perceptivas e se instalam na vida do sujeito de forma cada vez mais distinta e imediata. Fato indiciador da necessidade de educar alunos e professores para o universo midiático com a intenção de ampliar a capacidade analítica e a criticidade desses receptores (PIMENTEL, 2011, p.21).

Pimentel aborda a necessidade da educação para o universo midiático. Isso nos mostra que o projeto está no caminho certo, pois durante o debate percebeu-se que a manipulação da mídia no universo ingênuo da mãe se tornou a última e desesperada alternativa que encontrara para ajudar seu filho.

Apesar de o filme retratar uma época distinta da qual vivemos, percebeu-se durante o debate, que o filme tem grande semelhança com a realidade em que se encontram as famílias pobres de hoje, pois assim como a mãe de Roberto, a única alternativa de muitos pais de salvar a vida de seus filhos é leva-los a instituições educacionais ou instituições de caridade, que por muitas vezes sofrem por falta de recursos necessários à saúde, educação, segurança e lazer, conferindo uma péssima infraestrutura a essas instituições, como podemos perceber nas instituições públicas da comunidade de São Bernardo. As escolas de São Bernardo, como a FEBEM no filme, tem o apelo de ser uma instituição redentora, transformadora, escola de primeira geração, enquanto que na realidade observamos um sistema totalitário, opressor, desestimulador, que usa de métodos tradicionais e punições ultrapassadas, que não favorecem o ensino e aprendizagem. 


\section{EDUCAÇÃO, ARTES E INCLUSÃO}

VOLUME 11, NÚMERO 2, Ano 2015

Também se discutiu durante o debate, outro tema encontrado nas escolas de São Bernardo e no filme, a marginalização do negro e da pobreza, o racismo e o sistema fragilizado das instituições governamentais. Definimos o racismo como:

(...) uma ideologia, ou seja, um conjunto articulado de cultura, valores, posturas, comportamentos de um grupo (um pequeno grupo), que amplamente disseminado - embora de forma oculta ou subliminar - torna-se um pensamento social, uma forma de ver e explicar a vida e a realidade. $\mathrm{O}$ racismo, nesse sentido, é a crença na existência das raças (branca, negra, indígena e oriental) e na possibilidade da superioridade de uma sobre as outras (PAULA, 2005, p. 89).

Assim, percebemos na realidade de São Bernardo e no filme vários comportamentos que trazem o racismo e a superioridade do branco sobre o negro, injustiças e crimes que a comunidade bernardense vivencia dia após dia.

Voltando as atenções para o lado artístico do filme, vemos que, apesar do filme mostrar uma realidade cheia de imperfeições, o olhar da personagem central da história nos proporciona momentos de deleite a um mundo fantástico, imerso na imaginação, e sua habilidade criadora de verter a dura realidade, mostra-nos a capacidade de contornar seus problemas e transformá-los em situações agradáveis.

Outro filme também muito apreciado e debatido durante o Ciclo de Filme foi Capitães da areia, de 2011, dirigido por Cecília Amado. O filme tem como tema principal a vida de meninos de rua que vivem em um trapiche na cidade de Salvador. Pedro Bala, Professor, Gato, Sem-Pernas, Boa Vida e Dora, são personagens que Jorge Amado um dia criou para habitarem eternamente na memória de seus leitores. Agora, Cecília Amado nos emociona mostrando estes personagens imortais da literatura brasileira e mundial de forma profunda, inspiradora e reflexiva, trazendo a sociedade em que vivemos para o debate.

O debate do Ciclo de Filmes deu-se após os espectadores apreciaram o filme, como participantes ativos, observando-o “(...) por meio de seus diferentes modos e níveis de saber admirar, gostar, apreciar e julgar, culturamente aprendidos" (FERRAZ e FUSARI, 1999, p.17). Neste contexto, o debate seguiu com muitos questionamentos e depoimentos pessoais, vivências emotivas e cognitivas sobre violência, abandono, capoeira e religião. 


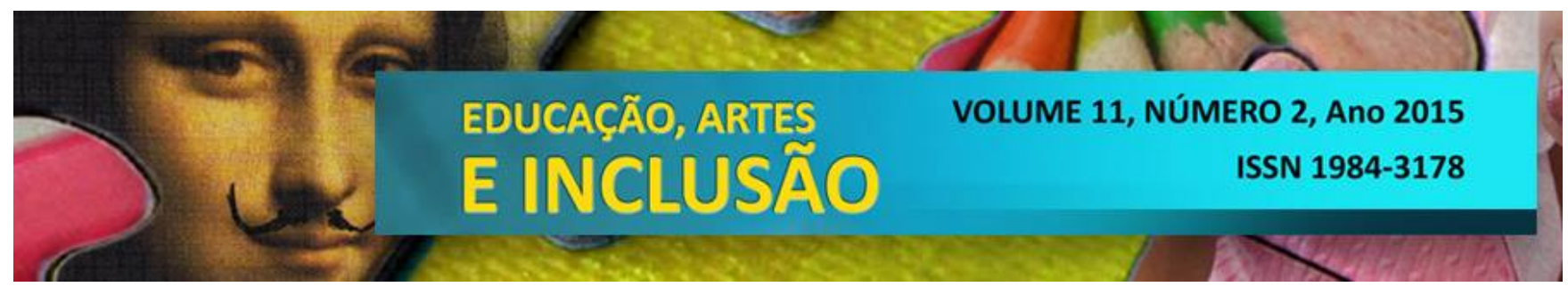

O filme que mais repercutiu comentários nos corredores antes e depois da exibição foi Hoje eu quero voltar sozinho.

A Figura 5 mostra o cartaz de divulgação do filme Hoje eu quero voltar sozinho, um filme dirigido, produzido e roteirizado por Daniel Ribeiro em 2014. No enredo, Leonardo é um adolescente cego, que tenta lidar com a mãe superprotetora ao mesmo tempo em que busca sua independência. Quando Gabriel, um novo aluno, chega à escola, novos sentimentos começam a surgir em Leonardo, fazendo com que ele descubra mais sobre si mesmo e sua sexualidade.

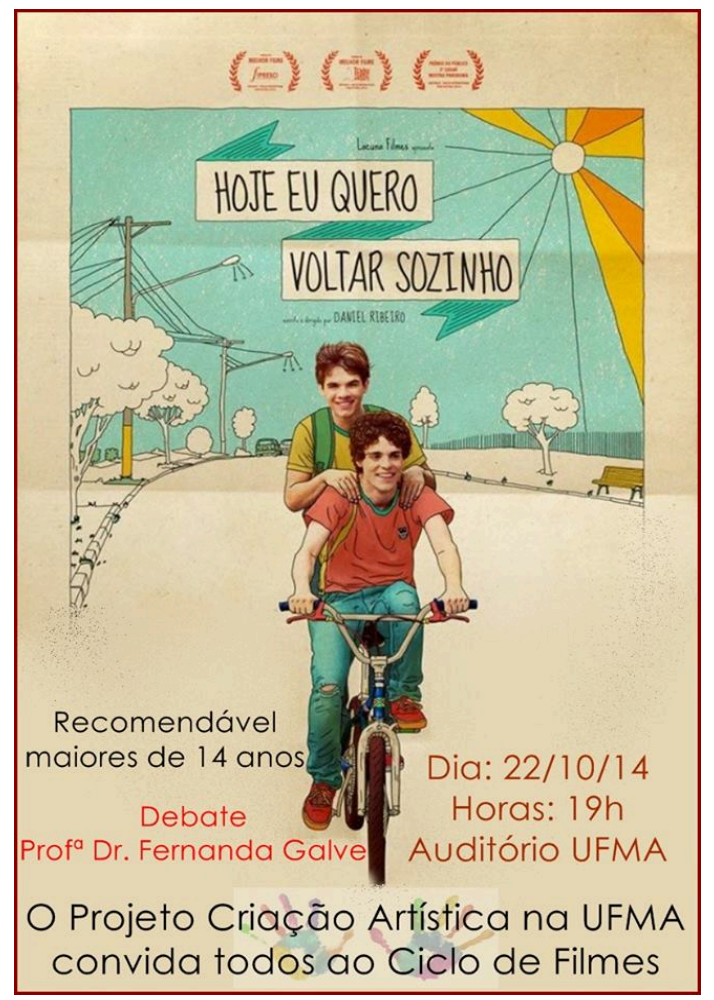

Figura 5: Cartaz de divulgação do filme Hoje eu quero voltar sozinho

A Professora doutora Fernanda Rodrigues Galve foi à mediadora do debate. O batepapo ficou principalmente em cima dos temas principais do filme: inclusão, gênero e diversidade. Falou-se sobre inclusão por meio da Declaração de Salamanca - Sobre os princípios políticos e práticas na área das Necessidades Educativas Especiais, da Lei $\mathrm{n}^{\circ}$ 
9394/1996 - Lei de Diretrizes e Bases da Educação Nacional e da Política Nacional de Educação Especial na Perspectiva da Educação Inclusiva.

Sobre o tema gênero e diversidade, o debate teve como base o livro "Diversidade e educação: intersecções entre corpo, gênero e diversidade, raça e etnia". Nele, os organizadores Sierra; Signorelli (2014) abordam sobre a importância da construção de uma sociedade pautada na equidade e na minimização das dicotomias entre os gêneros, na diminuição dos preconceitos, do sexismo, da homofobia, da lesbofobia, da transfobia, da bifobia, bem como de todas as outras manifestações de violências de gênero.

Com essas discussões, o Ciclo de Filme possibilitou aos espectadores a sensibilização, a problematização e a discussão de temas que fazem parte da realidade de nossa sociedade. Temas que são emergentes na sociedade brasileira, que fizeram com que os espectadores pudessem refletir sobre relações de gênero, diversidade sexual, diferentes manifestações de violência de gênero, a articulação de gênero com questões étnicas raciais e seus reflexos no campo da educação.

\section{Resultados}

Participaram do projeto mais de cento e cinquenta (150) pessoas ativamente, como também pessoas que participaram da exposição como espectadores. Dentre as cento e cinquenta, vinte (20) pessoas participaram como equipe executora, trinta e duas (32) nas oficinas de Artes Visuais e aproximadamente cem (100) no Ciclo de Filmes.

O projeto apresentou uma grande relevância, pois uniu a pesquisa, o ensino e a extensão, proporcionando aos participantes aquisições de novos conhecimentos. As atividades possibilitaram a união entre estes três eixos pedagógicos, pois este projeto de extensão está associado aos conteúdos das disciplinas de Artes Visuais do curso de Licenciatura em Linguagens e Códigos e ao Grupo de Estudos e Pesquisas Interdisciplinares sobre as Cidades, CITADINOS, UFMA. 
Deslocou-se a comunidade de São Bernardo para dentro do Campus da UFMA, para pesquisar, vivenciar e apreender sobre arte, com a metodologia teórico-prática, onde os participantes enriqueceram o repertório visual e desenvolveram o processo de criação. Nesse sentido, a relação entre ensino, pesquisa e extensão, pode conduzir a mudanças significativas nos processos de ensino e aprendizagem, colaborando efetivamente para a formação profissional da comunidade, dos estudantes e professores e fortalecendo os atos de aprender, de ensinar e de formar profissionais e cidadãos.

No Ciclo de Filmes, as atividades proporcionaram uma experiência única para muitos, pois o cinema mais próximo da cidade fica em outro estado a $120 \mathrm{~km}$ de distância. Muitos espectadores nunca tinham entrado numa sala de cinema. A equipe executora do projeto preparou o auditório num espaço agradável, num clima aconchegante, com muita pipoca e suco. No percorrer do projeto, gradativamente as salas foram ficando cada vez mais lotadas, criando um hábito na comunidade acadêmica e bernardense. Percebeu-se, assim, o quanto é importante o professor trabalhar com as mídias com seus educandos, principalmente em lugares que o cinema ainda não chegou.

O projeto Criação Artística na UFMA teve impacto científico, pois foi apresentado e publicado no XIV Encontro Humanístico, realizado em São Luís, MA. O projeto apresentou impacto tecnológico, pois se criou muitas imagens, por meio da fotografia e de vídeos sobre as Oficinas Artísticas, o Ciclo de Filmes e as Exposições. As práticas artísticas artesanais impulsionaram a econômica, pois as oficinas enriqueceram e valorizaram o resgate do trabalho manual, incentivando trocas de experiências, a elevação da autoestima, a descoberta de novas aptidões, contribuindo assim para o desenvolvimento da autonomia profissional e fazendo com que algumas pessoas ampliassem a renda familiar com as produções realizadas nas oficinas. Houve, também, impacto social, pois os participantes souberam se expressar e se comunicar mantendo uma atitude de busca pessoal e/ou coletiva, articulando a percepção, a imaginação, a emoção, a sensibilidade e a reflexão ao realizar e fruir produções artísticas, tornando-se cidadãos críticos e reflexivos. E, impacto ambiental, pois durante as Oficinas Artísticas foram reutilizados materiais, reciclando-os de uma maneira criativa e de forma consciente, trabalhando com a consciência ambiental. 


\section{Conclusão}

O projeto proporcionou um intercâmbio de experiências/conhecimentos entre comunidade e universidade. Essa aproximação entre o universo acadêmico e o popular, evidenciou-se em uma aprendizagem mais significativa, em relação ao conhecer e ao fazer artístico, que foi pensado e repensado várias vezes no intuito de propor uma nova experiência ao expectador, aproximando-o da realidade vivida e considerando essas experiências significativas.

As ações pedagógicas aconteceram por meio de um sistema inclusivo, democrático e aberto à diversidade, porque a Universidade é um espaço de socialização onde devem ser desenvolvidos o senso crítico e os valores éticos e morais que regem a sociedade. Ela tem como responsabilidade a ampliação dos horizontes culturais, pois é nela que convivemos com as diferentes formas de agir, pensar e se relacionar, fortalecendo as experiências significativas.

Pensando nesta responsabilidade cultural, o projeto possibilitou influências socioculturais, proporcionando aos participantes uma educação pautada nos sentidos. "Os sentidos fazem sentido, produzem conhecimento e impulsionam à ação na tentativa de transmitir saberes sobre o ser humano e o mundo" (PIMENTEL, 2011, p.15). Assim, o projeto se constituiu num embasamento teórico-prático, que viabilizou estratégias que possibilitaram uma produção de conhecimento significativa.

Por meio do Ciclo de Filmes, levando os expectadores a novas experiências visuais, fazendo do filme um instrumento didático, que favoreceu o ensino e aprendizagem e proporcionou aos participantes uma educação para a mídia, uma educação para ver, observar e refletir. Concluímos que levar propostas que visem experiências audiovisuais, como no caso a mostra de filmes, não só mantém a atenção dos participantes como os fez interagir, refletir e questionar acerca de assuntos que fazem parte do seu cotidiano, da realidade da nossa sociedade. 
As Oficinas Artísticas contribuíram aos participantes em relação ao fazer, ao contextualizar e ao fruir a arte, num ambiente descontraído e significativo, com muito aprendizado social, pedagógico, artístico e estético. O desenvolvimento expressivo dos participantes exteriorizou os sentimentos e as emoções, num processo de inter-relação com os outros. Estas oficinas constituíram-se num espaço onde os participantes puderam exercitar suas potencialidades perceptivas, imaginativas, fantasiosas e de criação.

\section{Referências}

BERNARDET, Jean-Claude. O que é cinema. 2 ed. São Paulo: Brasiliense, $1985 ?$.

BRASIL. Lei $\mathbf{n}^{\mathbf{0}}$. 9.394, de 20 de novembro de 1996. Estabelece as diretrizes e bases da educação nacional. Diário Oficial da União. Brasília, 1996. Disponível em: http://www.planalto.gov.br/ccivil 03/Leis/L9394.htm. Acesso em: 18 nov. 2015.

Ministério da Educação. Secretaria de Educação Especial. Política Nacional de Educação Especial na perspectiva da Educação Inclusiva. Brasília: MEC/SEESP, 2008. Disponível em: http://peei.mec.gov.br/arquivos/politica_nacional_educacao_especial.pdf. Acesso em: 18 nov. 2015

FERRAZ, Maria Heloísa Corrêa de Toledo, FUSARI, Maria F. de Resende e. Metodologia do ensino de arte. São Paulo: Cortez, 1999. - 2. ed.- (coleção magistério. $2^{\circ}$ grau. Série formação do professor).

HERNÁNDEZ, Fernando. Catadores da Cultura Visual: transformando fragmentos em nova narrativa educacional. Porto Alegre: Mediação, 2007.

LANIER, Vincent. Devolvendo Arte à Arte- Educação. In: BARBOSA, Ana Mae (org.). Arte- Educação: leitura no subsolo. - 9. ed. - São Paulo: Cortez, 2013.

LEITE, Sidney Ferreira. A formação do cinema no Brasil. São Paulo: Perseu Abramo, 2005.

MARX, Karl. Contribuição à Crítica da Economia Política. 3.ed. São Paulo: Martins Fontes, 2003. 
OLIVEIRA, Sandra Regina Ramalho e. O problema da leitura de imagens. Arte on linePeriódico on line de Artes. Volume 1: julho/outubro, 1999. Disponível em: http://www.ceart.udesc.br/Revista_Arte_Online/Volumes/artigosandra.htm. Acessado em 21 de setembro de 2015.

PAULA, Adilton de. Educar o Brasil com raça: "Das raças ao racismo que ninguém vê. In: SANTOS, Gevanilda; SILVA, Maria Palmira da (orgs.). Racismo no Brasil: percepções da discriminação e do preconceito no século XXI. São Paulo: Editora Fundação Perseu Abranmo, 2005.

PIMENTEL, Lucilla da Silveira Leite. Educação e cinema: dialogando para a formação de poetas. São Paulo: Cortez, 2011.

PNUD. Programa das Nações Unidas para o Desenvolvimento. Ranking decrescente do IDH-M dos municípios do Brasil. Atlas do Desenvolvimento Humano Programa das Nações Unidas para o Desenvolvimento (PNUD) (2000). Visitado em 11 de outubro de 2008. Disponível em: http://www.pnud.org.br/atlas/ranking/IDHM\%2091\%2000\%20Ranking\%20decrescente \%20\%28pelos\%20dados\%20de\%202000\%29.ht m. Acesso em: 13 nov. 2015.

SIERRA, Jamil Cabral; SIGNORELLI, Marcos Claudio (orgs.). Diversidade e educação: intersecções entre corpo, gênero e diversidade, raça e etnia. Matinhos: UFPR Litoral, 2014.

UNESCO. Declaração de Salamanca. Sobre Princípios, Políticas e Práticas na Área das Necessidades Educativas Especiais. Disponível http://portal.mec.gov.br/seesp/arquivos/pdf/salamanca.pdf. Acesso em: 18 nov. 2015.

VYGOTSKY, Lev Semyonovich. A Formação Social da Mente. São Paulo: Livraria Martins Fontes, 2002.

VIGOTSKI, Lev S.(Lev Semionovich), 1896-1934. Imaginação e criação na infância: ensaio psicológico: livro para professores. Apresentação e comentários: Ana Luiza Smolka. Tradução: Zoia Prestes. São Paulo: Editora Ática, 2009.

\section{Filmes}

Capitães da areia. Cecília Amado. Brasil: Imagem Filmes, 2011.

Hoje eu quero voltar sozinho. Daniel Ribeiro. Brasil: Vitrini Filmes, 2014. 


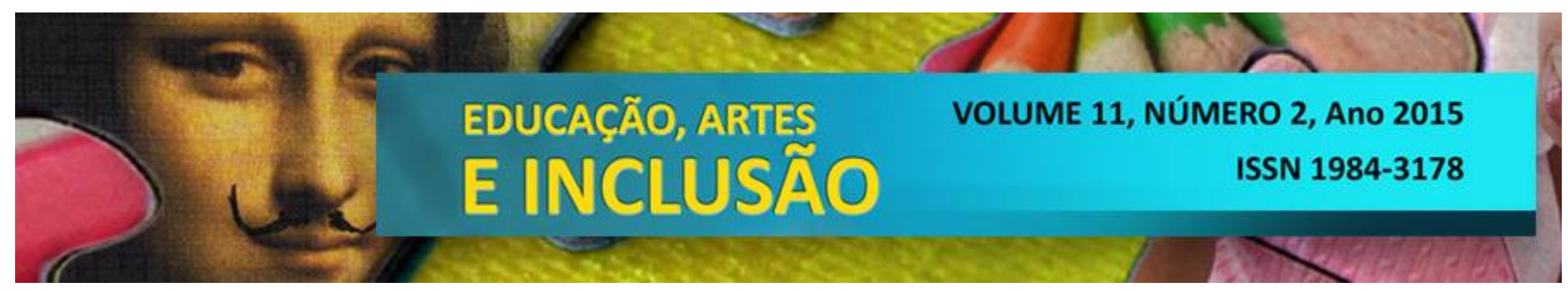

O contador de história. Luiz Villaça. Brasil: Warner Bros, 2009.

Janine Alessandra Perini - Professora de Artes Visuais do curso de Licenciatura em Linguagens e Códigos da Universidade Federal do Maranhão (UFMA), Campus de São Bernardo. Mestra em Artes Visuais pelo Programa de Pós-graduação da Universidade Estadual de Santa Catarina (UDESC). Membro do grupo de Estudos e Pesquisas Interdisciplinares sobre cidades. CITADINOS, UFMA. Contato: janine_perini@yahoo.com. 